\title{
Designing a Scale to Assess Family Nursing Practice among Public Health Nurses in Japan
}

\author{
Noriko Toyama ${ }^{1,2}$, Kayoko Kurihara', Mineko Muranaka ${ }^{3}$, Kokoro Shirai ${ }^{4}$, Kiyoko Kamibeppu ${ }^{1}$ \\ ${ }^{1}$ Department of Family Nursing, Graduate School of Medicine, The University of Tokyo, Tokyo, Japan \\ ${ }^{2}$ Department of Global Health, Graduate School of Health Sciences, University of the Ryukyus, Okinawa, Japan \\ ${ }^{3}$ Japanese Nursing Association, Tokyo, Japan \\ ${ }^{4}$ Department of Human Sciences, Faculty of Law and Letters, University of the Ryukyus, Okinawa, Japan \\ Email: ntoyama-tky@umin.ac.jp
}

How to cite this paper: Toyama, N., Kurihara, K., Muranaka, M., Shirai, K. and Kamibeppu, K. (2017) Designing a Scale to Assess Family Nursing Practice among Public Health Nurses in Japan. Health, 9, 1019-1028.

https://doi.org/10.4236/health.2017.97074

Received: May 3, 2017

Accepted: July 9, 2017

Published: July 12, 2017

Copyright (C) 2017 by authors and Scientific Research Publishing Inc. This work is licensed under the Creative Commons Attribution International License (CC BY 4.0).

http://creativecommons.org/licenses/by/4.0/

cc) (†) Open Access

\begin{abstract}
Background: The promotion of family nursing by public health nurses (PHN) presupposes an accurate assessment of the family nursing support they already provide. However, as there is no assessment tool for this purpose, this study aimed to develop a scale to assess family nursing currently provided by PHN. Methods: We developed the Family Nursing Practice Scale (FNPS) for PHN based on the results of a previous study. The content validity of the FNPS was established through discussion with three other researchers. A pilot study was conducted to confirm face validity. To confirm reliability and validity, an anonymous, self-reported questionnaire was sent to PHN working in municipal offices. The statistical analyses included the Kaiser-Meyer-Olkin (KMO), Barlett's Test of Sphericity, exploratory factor analysis (EFA), Cronbach's alpha, correlation coefficient and t-test. Results: Seven hundred fifty-four PHN participated in this study. Cronbach's alpha of FNPS was 0.94. The KMO measure was 0.948 , and Bartlett's Test of Sphericity was $\mathrm{p}<0.01$. Two factors together accounted for $63.2 \%$ of the variance in EFA. No items were excluded because of low loadings. Construct validity was confirmed through comparison with categories from a previous study. The correlation coefficient of FNPS and selected items of the Practice of Breastfeeding Support Scale was $r=0.56(p<0.01)$. The result of the $t$-test showed that the FNPS score of PNH who had received training in family nursing was significantly higher than that of PHN who had not $(t=-2.0 ; p<0.05)$. Conclusion: The reliability and validity of the FNPS were confirmed. The FNPS comprised 15 items and two factors. The score for "Active support for the family" was lower than "Support given with awareness of the family's situation." The findings of this study strongly suggested that the FNPS would be effective in clarifying the current state of family nursing provided by PHN and factors related to this activity and thus greatly assist the efforts of PHN to promote fam-
\end{abstract}


ily nursing.

\section{Keywords}

Family Nursing Practice Scale, Public Health Nurse, Scale Development

\section{Introduction}

The family structure and community relations are changing in today's Japan. For instance, the number of single-parent households is swelling due to a rising divorce rate [1] [2] and as community bonds weaken, young families, especially in urban settings, are left isolated from other members of their community. These changes might be one of the reasons behind the current increase in reported cases of child abuse [3].

Family nursing is recognized as an important practice for its potential to mitigate some of these conditions and has therefore been actively promoted throughout Japan [4]. Kinoshita [5] listed the reasons why family nursing are needed as follows: 1) People learn about health- and disease-related behaviors from other families; 2) The family as a whole is affected by the health problem(s) of individual members; 3) The family influences the individual's health, and vice versa; 4) It is more effective to provide health care to the whole family than on an individual basis; and 5) Social stability is bolstered through the promotion, maintenance, and recovery of family health.

Public health nurses (PHN) have been at work in the community for more than 70 years throughout Japan to promote health and disease-prevention and to provide other public health services. An outstanding instance of such services is the family nursing approach used by PHN to promote community health activities [6]. For example, when a PHN visits a household with a newborn to provide care, she simultaneously assesses the health state of other family members informally by looking for overt signs of possible disease or ill health including cough, underweight, bad complexion, and so on [7]. Should the PHN discover a health problem in the household, she would provide appropriate care. Thus the PHN serves not only the individual but also the family as a whole, often with the aid of several family assessment models including the family life ability model, the Calgary family intervention model, the Freedman family assessment model, and the family empowerment model [8]. As yet, however, there is no scale for assessing the quality of the family nursing practice provided by the PHN themselves.

Previous studies have developed scales or indicators to assess caring belief as well as the skills of nurses engaged in family nursing. Meiers [9] developed the Family Nursing Caring Belief Scale (FNCBS) for pediatric and neonatal intensive care unit nurses. A four-factor structure was revealed: ethical caring practices, system orientation to the family, child advocacy, and normalizing milieu. Simpson [10] developed and tested the Family Nursing Practice Scale (FNPS) in the 
field of psychiatric nursing. This self-reported questionnaire was designed to measure perceived changes in family nursing practice including attitudes toward working with families, critical appraisal of their family nursing practice, and reciprocity in the nurse-family relationship. Matsuzaka [11] developed a scale assessing the practical skills of PHN in family support activity. This scale comprised 78 items and seven factors including "Direct support to family", "Assessment and goal setting", "Evaluation of the family support", "Collecting information to understand the family", "Finding families who need support", "Family support based on community activity" and "Building a family support team" and is capable of assessing the skills and abilities of PHN to provide family support. However, Matsuzaka's scale is somewhat cumbersome with 78 items and cannot be used to assess the services currently provided by the PHN.

In 2004 Shibagaki [12] developed a questionnaire to assess family nursing practice provided by hospital nurses and visiting nurses in Japan, which included five categories of "Health and daily life of family", "Partnership with family", "Words of appreciation", "Showing consideration for the family's anxiety" and "Accepting the family's feelings" along with 23 items based on her review of the literature. The results showed that visiting nurses were more active in providing family nursing than hospital nurses. In 2009 Ishizawa [13] revised the questionnaire developed by Shibagaki to examine the factors related to family nursing practice provided by visiting nurse. She extracted 20 items out of 23 items with the same five categories as in the previous study and simplified the questions. For example, some of the items in Shibagaki's questionnaire conflated two questions. Such items were rewritten to include only one question. Ishizawa's study revealed that the family nursing practice score of nurses who had received formal training in family nursing was higher than that of nurses who had not. These findings suggested that learning family nursing skills had important implications for the quality of the visiting nurses' work.

The role of the PHN is closer to that of the visiting nurse than that of the hospital nurse. However, there are clearly differences as well. Therefore, this study aimed to develop a family nursing practice scale (FNPS) for PHN and to assess the current state of PHNs' family nursing practices to supply an empirical basis for improving their activities.

\section{Method}

\subsection{Study Design}

We developed the Family Nursing Practice Scale (FNPS) questionnaire for PHN based on the results of a previous study [13]. A likert scale ranging from 1 (never do) to 5 (always do) was chosen for its ease of use for both the assessors and the respondents. Content validity was established through discussion with three other researchers, two of whom provided family health nursing and one of whom had more than ten years' experience as a municipal PHN. A pilot study was conducted to confirm face validity.

To confirm reliability and validity, an anonymous self-reported questionnaire, 
a letter explaining the study, the instructions, and a return envelope were sent to the directors of maternal and child health $(\mathrm{MCH})$ divisions in all the municipalities throughout Japan, who were requested to select one PHN as a respondent. The PHNs then returned the completed questionnaires to the researchers.

\subsection{Participants}

PHN working at municipal offices participated in this study. To control for potential confounders, only PHN working for MCH services without midwife qualifications and those with five to 15 years of work experience were included. If no PHN in a given municipality met these conditions, any PHN with the closest number of years of work experience to the requirements of the study was recruited.

\subsection{Data Analysis}

SPSS version 23 for Windows was used and $\mathrm{p}<0.05$ was considered statistically significant. The Kaiser-Meyer-Olkin (KMO) measure was used for sampling adequacy (using a cut-off of 0.5), and Barlett's Test of Sphericity (using a cut-off $\mathrm{p}<0.01$ ) was used to ensure the appropriateness of the data set for exploratory factor analysis. To find the factor structure, factor analysis (principal factor method, promax rotation) was conducted. Cronbach's alpha was calculated to examine the reliability of the scale. To confirm criterion-related validity, items from the Practice of Breastfeeding Support Scale (PBSS) [14], which assesses individual and family support by PHN, were selected for analysis. Spearman's correlation coefficient was calculated for the FNPS and selected items of the PBSS total scores. Independent samples t-test was used to confirm known-groups validity. The statistics for each variable were calculated to delineate more clearly the current state of family nursing provided by PHN.

\subsection{Ethical Approval}

Ethical approval was obtained from the ethical review board of the Faculty of Medicine of The University of Tokyo (Clearance No. 3035).

\section{Results}

\subsection{Characteristics of the Participants}

Of the 1750 questionnaires sent, 831 were returned (response rate: $47.5 \%)$. Seventy-seven were excluded from analysis due to missing data. Therefore, the valid response rate was $43.1 \%$ (754). Table 1 shows that $99.7 \%$ of the respondents were female and that the average age was 35.5 years ( $S D=6.2$, range: $22-62$ ). The average length of work experience was 10.7 years ( $\mathrm{SD}=5.5$, range: $0-33$ ). Educational background consisted of vocational school (52\%), junior college (17.4\%), university (30.4\%), and graduate school (1.1\%). Participants with experience of childbirth constituted $65.8 \%$ of the respondents and included those with partners who had assisted with some aspect of the childbirth. 
Table 1. Characteristics of participants.

\begin{tabular}{ccccc}
\hline & Category & $\mathrm{n}(\%)$ & Average \pm SD & (Range) \\
\hline Sex & Male & $2(0.3)$ & & \\
Work experience & Femal & $752(99.7)$ & & \\
Final education & Vocational school & $389(52.0)$ & \\
& Junior college & $131(17.4)$ & \\
& University & $229(30 . .4)$ & \\
& Graduate School & $8(1.1)$ & \\
& No answer & $1(0.1)$ & \\
Experience of childbirth & Yes & $496(65.8)$ & \\
(respondent or their partner) & No & $257(34.1)$ & \\
& No answer & $1(0.1)$ & \\
& Yes & $544(72.1)$ & \\
Learned family nursing & No & $193(25.6)$ \\
& No answer & $17(2.3)$ \\
\hline
\end{tabular}

\subsection{Factor Analysis of Family Nursing Practice}

The KMO measure was 0.948 , indicating sampling adequacy. Sufficient variability in the data, confirmed by Barlett's Test of Sphericity $(p<0.01)$, demonstrated the validity of the data for exploratory factor analysis.

Two factors together accounted for $63.2 \%$ of the variance. No items were excluded because of low loadings (below 0.3 ). Analysis produced two factors including 15 items (Table 2).

Latent variables were labeled as follows: Factor 1) Active support for the family (10 items); and Factor 2) Support given with awareness of the family's situation (5 items). The factor contribution was 8.29 for Factor 1, 1.19 for Factor 2.

\subsection{Reliability and Validity of the FNPS}

\subsubsection{Internal Consistency}

Cronbach's alpha was calculated to verify the reliability of FNPS. The reliability of FNPS was 0.93 for Factor 1, 0.86 for Factor 2, and 0.94 overall.

\subsubsection{Face Validity}

The participants in the pilot study were 22 PHNs. The results of the pilot study showed that there were no data missing from the questionnaire and no complaints about difficulties in answering the questions.

\subsubsection{Construct Validity}

The two factors resulting from factor analysis were compared with five categories from a previous study on PHN family nursing practice: Category 1) Accepting family's feelings; Category 2) Showing consideration for the family's anxiety; Category 3) Health and daily life of family; Category 4) Words of appreciation; 
Table 2. Factor analysis of Practice of Family Nursing Scale (Cronbach alpha $=0.94)$.

\begin{tabular}{|c|c|c|}
\hline & 1 & 2 \\
\hline \multicolumn{3}{|l|}{ Factor 1: Active support for the family ( $\alpha=0.93$ ) } \\
\hline (6) I support each family. & 0.70 & 0.09 \\
\hline (7) I tell the family that I am their supporter. & 0.63 & 0.15 \\
\hline (8) I am a worker who understands how the family truly feels. & 0.80 & 0.06 \\
\hline (9) I communicate purposefully with the family. & 0.80 & 0.07 \\
\hline (10) I take the initiative to approach the family. & 0.75 & 0.09 \\
\hline (11) I try to create opportunities to converse with the family. & 0.81 & 0.01 \\
\hline (12) I try to see things from the family's perspective when I talk to them. & 0.50 & 0.32 \\
\hline (13) I support the family when they express their feelings. & 0.64 & 0.13 \\
\hline (14) I encourage the self-expression of the family. & 0.83 & 0.01 \\
\hline (15) I intervene in the family's problems. & 0.89 & -0.27 \\
\hline \multicolumn{3}{|l|}{ Factor 2: Support given with awareness of the family's situation. $(\alpha=0.86)$} \\
\hline $\begin{array}{l}\text { (1) I want to be aware of what the family considers to be important in my } \\
\text { interactions with them? }\end{array}$ & -0.04 & 0.81 \\
\hline (2) I always keep the family in mind from the first. & -0.19 & 0.98 \\
\hline (3) I express my appreciation to the family. & 0.14 & 0.73 \\
\hline (4) I provide support while being aware of my influence on the family. & 0.05 & 0.79 \\
\hline (5) I understand the health status of the family. & 0.17 & 0.60 \\
\hline Factor contribution & 8.29 & 1.19 \\
\hline Cumulative contribution ratio (\%) & $55.3 \%$ & $7.9 \%$ \\
\hline
\end{tabular}

Principal factor method, promax rotation.

and Category 5) Partnership with family [12]. Factor 1 included Categories 1, 2, and most of the items in Category 5, while Factor 2 included Categories 3, 4, and one of the items in Category 5. The exceptions were one item from Category 5, "I always kept the family in mind from the first" included in Factor 2.

\subsubsection{Criterion-Related Validity}

Criterion-related validity was assessed by calculating Spearman's correlation coefficient between the FNPS total score and 12 items selected from the PBSS total score $(r=0.56, p<0.01)$. A significant positive correlation was observed between the FNPS and PBSS.

\subsubsection{Known-Groups Validity}

The result of the t-test showed that the FNPS score of PNH who had received training in family nursing was significantly higher than that of PHN who had $\operatorname{not}(\mathrm{t}=-2.0 ; \mathrm{p}<0.05)$.

\subsection{Practice of Family Nursing}

The mean of the total FNPS was 3.7 ( $\mathrm{SD} \pm 0.6$; see Table 3 ). The mean was 3.5 $(\mathrm{SD} \pm 0.7)$ for Factor 1 and $4.1( \pm 0.6)$ for Factor 2. "I always kept the family in 
Table 3. The family nursing practice of public health nurses.

\begin{tabular}{|c|c|c|c|}
\hline & Mean & $\pm \mathrm{SD}$ & (Range) \\
\hline Factor 1: Active support for the family & 3.5 & \pm 0.7 & $(1-5)$ \\
\hline (6) I support each family. & 3.2 & \pm 1.0 & $(1-5)$ \\
\hline (7) I tell the family that I am their supporter. & 3.5 & \pm 1.0 & $(1-5)$ \\
\hline (8) I am a worker who understands how the family truly feels. & 3.4 & \pm 0.9 & $(1-5)$ \\
\hline (9) I communicate purposefully with the family. & 3.6 & \pm 0.9 & $(1-5)$ \\
\hline (10) I take the initiative to approach the family. & 3.8 & \pm 0.9 & $(1-5)$ \\
\hline (11) I try to create opportunities to converse with the family. & 3.5 & \pm 0.9 & $(1-5)$ \\
\hline (12) I try to see things from the family's perspective when I talk to them. & 3.9 & \pm 0.9 & $(1-5)$ \\
\hline (13) I support the family when they express their feelings. & 3.7 & \pm 0.9 & $(1-5)$ \\
\hline (14) I encourage the self-expression of the family. & 3.5 & \pm 0.9 & $(1-5)$ \\
\hline (15) I intervene in the family's problems. & 3.0 & \pm 0.9 & $(1-5)$ \\
\hline Factor 2: Support given with awareness of the family's situation & 4.1 & \pm 0.6 & $(2-5)$ \\
\hline $\begin{array}{l}\text { (1) I want to be aware of what the family considers to be important in my } \\
\text { interactions with them? }\end{array}$ & 4.0 & \pm 0.7 & $(2-5)$ \\
\hline (2) I always keep the family in mind from the first. & 4.3 & \pm 0.7 & $(2-5)$ \\
\hline (3) I express my appreciation to the family. & 4.1 & \pm 0.8 & $(1-5)$ \\
\hline (4) I provide support while being aware of my influence on the family. & 4.0 & \pm 0.8 & $(1-5)$ \\
\hline (5) I understand the health status of the family. & 4.1 & \pm 0.8 & $(1-5)$ \\
\hline Average & 3.7 & \pm 0.6 & $(2-5)$ \\
\hline
\end{tabular}

mind from the first" had the highest mean among all the items (M 4.3, SD \pm 0.7 ), and "I intervene in the family's problems" had the lowest mean (M 3.0, SD \pm $0.9)$.

\section{Discussion}

\subsection{Reliability of the FNPS}

Cronbach's alpha indicated that all factors exceeded the reference value, thereby ensuring the reliability of the scale.

\subsection{Validity of the FNPS}

The validity of the FNPS was assessed in terms of content validity, face validity, construct validity, and known-groups validity.

\subsubsection{Content Validity of the FNPS}

The FNPS was based on a previous study of family nursing practice by home visiting nurses in Japan [13], and was revised following a discussion of the pilot study by a panel of experts to ensure content validity.

\subsubsection{Construct Validity of the FNPS}

The construct validity was assessed through a comparison with the categories 
used in the aforementioned study and the results of exploratory factor analysis [12]. The two factors extracted were almost identical to those of the previous study and indicated construct validity. All items showed higher factor loadings than the other factors at greater than 0.5. "I always kept the family in mind from the first" was included in Factor 2, "Support given with awareness of the family's situation" in this study. Although in a previous study this item was placed in the "Partnership with family" category, in which most of the other items were included in Factor 1, we consider that it was correct to include it in Factor 2 based on the similarity of content.

\subsubsection{Criterion-Related Validity}

A significant positive correlation was observed between the FNPS total score and the selected PBSS total score demonstrating criterion-related validity for the FNPS.

\subsubsection{Known-Groups Validity}

The FNPS score of PNH who had received training in family nursing was significantly higher than that of PHN who had not, thus demonstrating knowngroups validity for the FNPS.

\subsection{Utilization of FNPS}

The results of the FNPS showed that the score for "Active support for the family" was lower than "Support given with awareness of the family's situation." In particular, the score for "I intervene in the family's problems" was extremely low, indicating that the PHN did not provide satisfactory support. Previous studies which assessed family nursing provided by visiting nurses also showed that items related to "I intervene in the family's problems" had lower average scores than other items [12] [13]. These findings suggest two applications of the result of the FNPS in the practice of public health nurse activities. The first is its use in more accurately assessing family nursing support with the aim of promoting family nursing practice by PHN. The second is its use in strengthening the weaknesses in family nursing practice by PHN through improving training methods, especially with regard to intervention in a family's problems (e.g., "Active support for the family").

\section{Limitations}

Test-retest reliability was not confirmed in this study. Therefore, further studies are needed to improve the family nursing practice assessment scale for PHN.

\section{Conclusions}

The reliability and validity of the FNPS were confirmed by the results of our analyses. The FNPS comprised 15 items and two factors including "Active support for the family" and "Support given with awareness of the family's situation." The score for "Active support for the family" was lower than "Support given with awareness of the family's situation." 
The findings of this study strongly suggested that the FNPS would be effective in clarifying the current status of, and the factors related to, family nursing services provided by PHN and thus contribute to promoting family nursing by PHN.

\section{Acknowledgements}

We are grateful to the PHNs who took the time to answer the questionnaire. We would like to express our gratitude to the faculty and members of the Department of Family Nursing, Graduate School of Medicine, School of Health Science \& Nursing in the University of Tokyo.

\section{Conflict of Interest}

We declare no conflict of interest.

\section{Source of Funding}

This study was funded by Grants-in-Aid for scientific research expenses of the Ministry of Education, Culture, Sports, Science and Technology (grant number 2139 0589).

\section{Contributions}

Noriko Toyama: study design, data collection, data input, data analysis, discussion, and finalization of the manuscript.

Mineko Muranaka: study design, data collection, discussion, and reviewing of the paper.

Kayoko Kurihara: study design, data analysis, discussion, and reviewing of the paper.

Kokoro Shirai: data analysis, discussion, and reviewing of the paper.

Kiyoko Kamibeppu: supervised all the processes involved in this study.

All authors read and approved the final manuscript.

\section{References}

[1] Ministry of Health, Labour and Welfare. (2009) Statistics about the Divorce. http://www.mhlw.go.jp/toukei/saikin/hw/jinkou/tokusyu/rikon10/01.html

[2] Ministry of Health, Labour and Welfare. (2012) Result of Comprehensive Survey of Living Conditions.

http://www.mhlw.go.jp/toukei/saikin/hw/k-tyosa/k-tyosa12/dl/02.pdf

[3] Ministry of Health, Labour and Welfare. (2016) Result of Child Abuse. http://www.mhlw.go.jp/seisakunitsuite/bunya/kodomo/kodomo_kosodate/dv/dl/ab out-01.pdf

[4] Suzuki, K. and Watanabe, H. (1993) A Review of Literature on Development of Family Nursing. Journal of Graduate School of Nursing, Chiba University, 15, 1-8.

[5] Kinoshita, Y. (2002) Nursing Family. Studies of Oita University of Nursing and Health Sciences, 2, 55-57.

[6] Suzuki, K. (2006) Development Process of Family Nursing. In: Suzuki, K. and Watanabe, H., Eds., Family Nursing, $3^{\text {rd }}$ Edition, Japanese Nursing Association Pub- 
lishing Company, Tokyo, 4-8.

[7] Yonabaru, S. (1983) Public Health Nurse in Okinawa. Azuma-do, 16-17.

[8] Nakayama, M. (2008) Representative Assessment Model. In: Yamazaki, A. and Hara, R., Eds., Family Nursing, Nankodo, Tokyo, 76-91.

[9] Meiers, S.J., Tomlinson, P. and Peden-McAlpine, C. (2007) Development of the Family Nurse Caring Belief Scale. Journal of Family Nursing, 13, 484-502. https://doi.org/10.1177/1074840707310734

[10] Simpson, P. and Tarrant, M. (2006) Development of the Family Nursing Practice Scale. Journal of Family Nursing, 12, 413-425. https://doi.org/10.1177/1074840706290806

[11] Matsuzaka, Y. and Arakida, M. (2017) Development of a Scale Facilitating the Assessment of Public Health Nurses' Practical Skills for Family Support: Analysis of Reliability and Validity. Journal of Family Nursing, 22, 74-86.

[12] Shibagaki, T. (2004) Differences of Recognition and Behavior between Hospital Nurses and Visiting Nurses in Family Nursing. Vol.29, Reports of Nursing Research, Nursing Teacher's Course of Center for Professional Education, Kanagawa University of Human Services, 258-265.

[13] Ishizawa, M., Tomioka, S., Ohtake, M., Akama, A., Suzuki, I., Kobayashi, A., Sato, C. and Kanoya, Y. (2009) The Actual Situation of Visiting Nurses' View of a Family and Family Nursing Practice and Factors Affecting Visiting Nurses' Family Nursing Practice. Yamagata Medical Journal, 27, 79-88.

[14] Toyama, N., Muranaka, M., Kurihara, K., Shirai, K. and Kamibeppu, K. (2017) Designing a Scale to Assess Breastfeeding Support among Public Health Nurses in Japan. Health, 9, 964-974. https://doi.org/10.4236/health.2017.96069

Submit or recommend next manuscript to SCIRP and we will provide best service for you:

Accepting pre-submission inquiries through Email, Facebook, LinkedIn, Twitter, etc. A wide selection of journals (inclusive of 9 subjects, more than 200 journals)

Providing 24-hour high-quality service

User-friendly online submission system

Fair and swift peer-review system

Efficient typesetting and proofreading procedure

Display of the result of downloads and visits, as well as the number of cited articles

Maximum dissemination of your research work

Submit your manuscript at: http://papersubmission.scirp.org/

Or contact health@scirp.org 